\title{
Condutividade hidráulica saturada em um solo aluvial do perímetro irrigado de São Gonçalo, PB
}

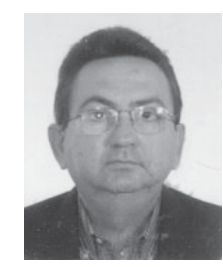

\author{
Aurelir N. Barretoํ, Gilvan R. de Oliveira² ${ }^{2}$ Luís C. Nogueira' ${ }^{1}$ \& Walane M.P. de M. Ivo \\ 1 Embrapa Tabuleiros Costeiros. Av. Beira Mar, 3250, C.P. 44, CEP 49001-970, Aracaju, SE. Fone: (79) 217-1300. \\ E-mail: aurelir@cpatc.embrapa.br (Foto) \\ 2 Departamento de Engenharia Agrícola/UFPB (Aposentado) \\ ${ }^{3}$ Embrapa Tabuleiros Costeiros. Escritório Regional de Pesquisa de Rio Largo, AL
}

Protocolo 073 - 27/06/2000

\begin{abstract}
Resumo: Realizaram-se testes de campo, com o objetivo de se caracterizar a variabilidade espacial da condutividade hidráulica $\left(\mathrm{K}_{0}\right)$ num solo aluvial, na Estação Experimental da Embrapa Algodão, em São Gonçalo, Paraíba, em 19 pontos de uma área de 18 ha. As profundidades do fundo dos poços situaram-se entre 1,0 e 1,65 m, considerando-se que a profundidade projetável do sistema drenante se situa nessa faixa da maioria das áreas irrigadas do Nordeste brasileiro. A amplitude de variação obtida de $\mathrm{K}_{0}\left(0,02\right.$ a $\left.1,71 \mathrm{~m} \mathrm{~d}^{-1}\right)$ mostra-se como resultado comum da maioria dos solos aluviais, resultante de processos de evolução do solo estudado, da gênese e da complexidade geomorfológica.
\end{abstract}

Palavras-chave: drenagem, condutividade hidráulica, solo aluvial

\section{Saturated hydraulic conductivity in an alluvial soil of irrigated district of São Gonçalo, PB}

\begin{abstract}
Field tests were carried out to characterize spatial variability of saturated hydraulic conductivity $\left(\mathrm{K}_{0}\right)$ in an alluvial soil at Embrapa-cotton Experimental Station, in São Gonçalo, Paraíba, Brazil. In an 18 ha area nineteen measurements of saturated $K_{0}$ were taken within 1.0 and $1.65 \mathrm{~m}$ depth in the soil profile, as most of the drainage systems in the irrigated areas of the Northeast Brazilian region are installed in this depth interval. Measured $\mathrm{K}_{0}$ values varied from 0.02 to $1.71 \mathrm{~m} \mathrm{~d}^{-1}$, agreeing with other results commonly obtained for alluvial soils. The observed $\mathrm{K}_{0}$ variability results from natural soil development process, its genesis and geomorphologic complexity.
\end{abstract}

Key words: drainage, hydraulic conductivity, alluvial soil

\section{INTRODUÇÃO}

O entendimento da hidrodinâmica em solos aluviais começa com o estudo e com a análise mecânica do material de origem e evolução, quanto ao aspecto textural, dos constituintes (composição ganulométrica) porque, em áreas irrigadas, os níveis de umidade no solo são influenciados pelo manejo da água na superfície e pela capacidade de drenagem interna na zona radicular, função de alguns parâmetros de solo. Entre os parâmetros físicos de solo para fins de drenagem, a condutividade hidráulica do solo saturado $\mathrm{K}_{0}$, medida no campo, tem a maior importância no dimensionamento e planejamento da drenagem interna do solo, particularmente importante quando se busca a eficácia do domínio hidrológico para uma decisão correta dos critérios de drenagem, em termos de espaçamento entre drenos, uma vez que o valor de $\mathrm{K}_{0}$, representa a constante de proporcionalidade entre o gradiente e o fluxo de um meio poroso. De acordo com Beltrán (1986), $\mathrm{K}_{0}$ depende da fluidez da água, que é proporcional a sua viscosidade e densidade, e da macroporosidade do solo que, por sua vez, é função da textura e da estrutura.
Ante esses fatores e grau de variabilidade esperados surge, então, uma outra questão fundamental: sob tais condições de solo, que procedimento adotar na escolha de um único valor para a condutividade hidráulica, que seja adequado ao dimensionamento de um sistema de drenagem em solos aluviais?

A determinação de $\mathrm{K}_{0}$ pode ser feita através de métodos de laboratório e de campo, em que os de laboratório mais usuais, são: permeâmetro de carga constante e carga variável. No campo, destacam-se os métodos que usam o princípio do fluxo contínuo, como o furo de trado (poço), os de fluxo constante, sendo que o princípio do fluxo contínuo é mais utilizado; os mais aplicados são o do furo de trado (não aconselhado para solos arenosos) e o método de Porchet, também conhecido como método inverso, uma vez que mede a $\mathrm{K}_{0}$ na ausência do lençol freático.

Os vertissolos estão sujeitos a estágios de umedecimento e secagem, de modo que os valores de $\mathrm{K}_{0}$ variam com a estação do ano, sendo menores nos períodos úmidos e maiores nos períodos secos (Bentley et al.,1989). Estudos de variabilidade sazonal são, portanto, importantes para planejamentos de drenagem. 
Os solos argilosos mostram que a condutividade hidráulica sofre pequenos acréscimos quando o solo é drenado (ElMowellhi \& van Shilfgaarde, 1982) porque há um aumento na atividade biológica, gerando aumento na porosidade estrutural. Nos solos orgânicos há decréscimo dos valores de $\mathrm{K}_{0}$, porque a perda de matéria orgânica é responsável pela estabilidade estrutural do solo.

Back et al. (1990) afirmam, que para a aplicação das equações de drenagem em regime variável, deve-se conhecer a condutividade hidráulica do solo saturado, a macroporosidade, a estratigrafia do perfil, os parâmetros geométricos do sistema, o critério de drenagem e a recarga do lençol freático; entretanto, essas variações podem, também, estar associadas a efeitos de outros parâmetros físicos de solo. A condutividade hidráulica depende da textura, do arranjo das partículas (estrutura), da dispersão das partículas finas e da sua densidade, e da massa sólida. Do ponto de vista da fluidez, segundo Beltran (1986), depende da fluidez do líquido, que é proporcional à sua viscosidade e densidade.

Numa ação de pesquisa elaborada para se estudar parâmetros de drenagem de terras irrigadas, focando solos aluviais de alguns vales da região Nordeste estudou-se, também, a variabilidade espacial da condutividade hidráulica saturada, $\mathrm{K}_{0}$, por meio das características hidrodinâmicas do solo da área experimental da Embrapa Algodão. Esta tarefa constituiu-se em objetivo específico, gerando um exercício no campo, essencial para fins de aplicação em drenagem agrícola.

\section{MATERIAL E MÉTODOS}

Os testes foram realizados no ano de 1995, na Estação Experimental de São Gonçalo, PB, sob as coordenadas geográficas $6^{\circ} 45^{\prime} \mathrm{S}$ e $38^{\circ} 10^{\prime} \mathrm{W}$, na ecorregião fisiográfica do Vale do Rio Piranhas.

A condutividade hidráulica do solo saturado, $\mathrm{K}_{0}$, foi medida em 19 pontos de teste, locados em linhas paralelas às estruturas hidráulicas (canais de irrigação e de drenagem), espaçados $100 \mathrm{~m}$ no sentido longitudinal (pontos circulados), distribuídos numa área de relevo plano (sistematizada) com formato irregular, medindo 18 ha. Utilizou-se o método de furo de trado, descrito por Pizarro (1978) e Millar (1988) para medir a condutividade hidráulica saturada, tanto na ausência (método de Porchet) como na presença do lençol freático. A instalação dos furos (poços) no perfil do solo foi realizada no eixo vertical, com trados agrológicos de $75 \mathrm{~mm}$ de diâmetro.

Para a execução do trabalho no campo, utilizou-se um instrumento composto de um suporte-referencial, trena de aço e um flutuador (bóia) para medir a velocidade de ascenção da água (Figura 1) e uma bomba sucção manual, utilizada para rebaixamento do nível d'água no poço, antes do início dos testes.

As profundidades do fundo dos poços situaram-se num intervalo entre 1,00 e 1,65 m, em relação à superfície, e a caracterização físico-hídrica dos perfis nos 19 pontos de testes está apresentada na Tabela 1, incluindo-se as camadas abaixo da zona dos testes, procedimento justificável porque, segundo Beltrán (1986), baseado na simplificação do conceito de fluxo tridimensional de Dupuit, ocorre predominância do fluxo horizontal em direção aos drenos, quando instalados na condição de lençóis freáticos extensos na área, com as linhas de drenagem

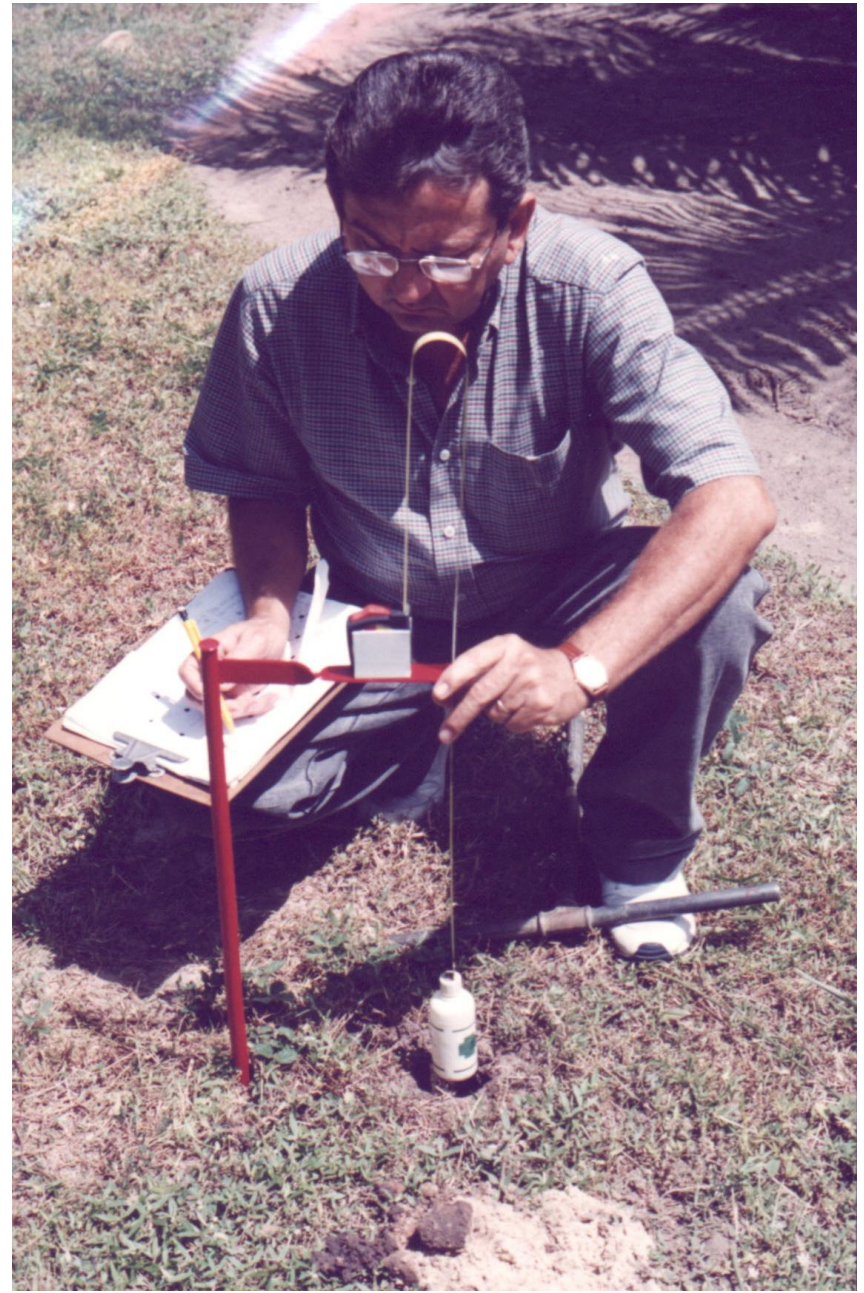

Figura 1. A aspecto operacional da determinação da condutividade hidráulica do solo saturado, $\mathrm{K}_{0}$, no campo, através do método do furo de trado, na ausência e na presença do lençol freático

instaladas acima da camada de impedimento. Outra justificativa para esse procedimento metodológico é que a camada escolhida para os testes corresponde, via de regra, à profundidade de instalação da rede de drenagem, nas condições de solos aluviais dos vales do Nordeste Brasileiro.

\section{RESULTADOS E DISCUSSÃO}

Os resultados da caracterização física e hídrica dos materiais de solo nos 19 perfis de testes estão apresentados na Tabela 1.

A Figura 2 mostra a variabilidade espacial, em profundidade, da condutividade hidráulica calculada a partir dos dados obtidos em campo nos 19 pontos de teste situados numa camada representativa de uma região efetiva de fluxo, na direção de um sistema drenante. Observa-se que a amplitude de variação foi alta nas diferentes profundidades entre 1,00 e 1,65 m, com valores da condutividade hidráulica variando de 0,02 a $1,71 \mathrm{~m} \mathrm{~d}^{-1}$. Valores de $0,06,0,06$ e 0,02 , foram verificados nos pontos de teste 6,7 e 8 , respectivamente, nas profundidades de 1,32, 1,50 e $1,50 \mathrm{~m}$, em horizontes cuja composição granulométrica de partículas finas foi de $28 \%$ de silte e $21 \%$ de argila.

$\mathrm{O}$ valor de $\mathrm{K}_{0}$ no perfil do solo pode ser altamente variável, pois difere não somente entre as camadas de solo mas, também, 
Tabela 1. Caracterização físico-hídrica dos materiais de solo coletados em 19 perfis de testes de condutividade hidráulica saturada, num solo aluvial do Perímetro Irrigado de São Gonçalo, PB, 1995

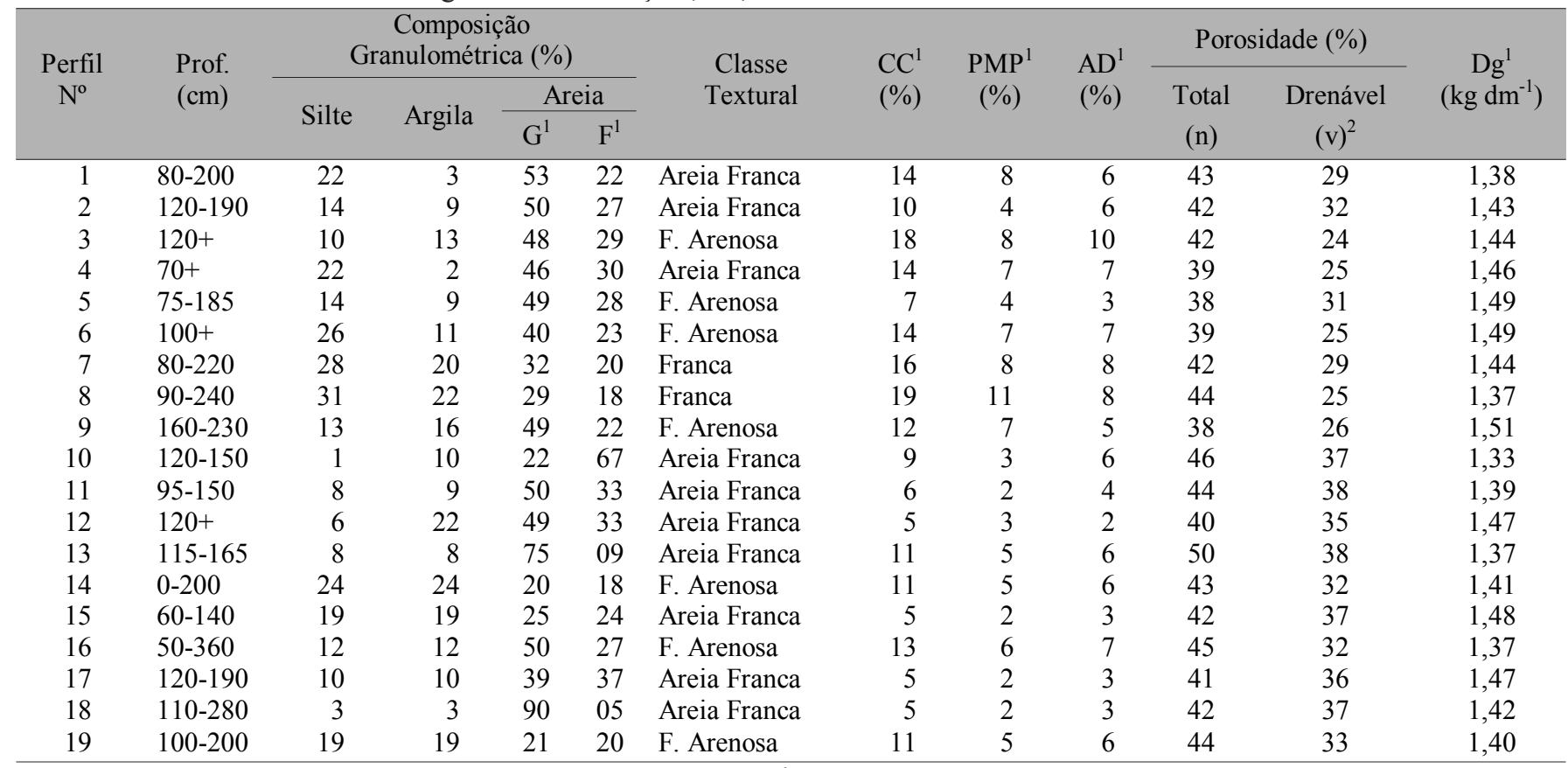

G - Grossa; F - Fina; CC - Capacidade de campo; PMP - Ponto de murchamento permanente; AD - Água disponível; Dg - Densidade global

${ }^{2}$ Estimada de acordo com a expressão $\mathrm{v}=\mathrm{n}-\mathrm{CC}$, com CC à base de volume

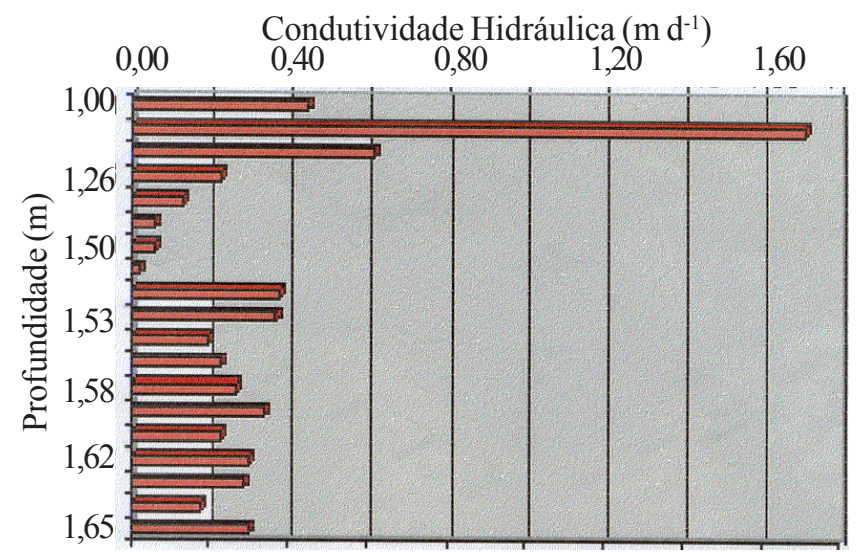

Figura 2. Variabilidade espacial vertical da condutividade hidráulica saturada, $\mathrm{k}_{0}$, num solo aluvial do Perímetro Irrigado de São Gonçalo, PB

dentro da mesma camada. Como as linhas de drenagem subsuperficial são instaladas, via de regra, nas profundidades entre 1 e $2 \mathrm{~m}$, em solos aluviais, o valor de $\mathrm{K}_{0}$ é importante tanto para esta zona como para zonas mais profundas, onde a dinâmica de fluxo continua em maior ou menor intensidade. Assim, baixas condutividades podem ser encontradas em argilas montmoriloníticas, em solos de textura fina, e vertissolos.

Na Figura 3 observa-se o comportamento da superfície de valores gerada a partir dos cálculos da condutividade hidráulica na área de estudo, incluindo 18 ha e no seu entorno na forma retangular para enquadramento sob as dimensões $\mathrm{X}, \mathrm{Y}$ e Z, atendendo critérios de execução do software utilizado. $\mathrm{O}$ maior valor de $\mathrm{K}_{0}\left(1,71 \mathrm{~m} \mathrm{dia}^{-1}\right)$ foi medido num horizonte de textura areia franca, com apenas $1 \%$ de silte e $10 \%$ de argila, na camada entre 1,20 e 1,50 m, no perfil de teste número 10 (Tabela 1) visualizado na Figura 4, em forma de "cone". Dos 19 testes realizados, 11 resultaram em condutividades entre 0,20 a $0,40 \mathrm{~m} \mathrm{~d}^{-1}$.
Intervalos de magnitude da condutividade hidráulica entre $0,20 \mathrm{e} 0,50 \mathrm{~m} \mathrm{~d}^{-1}$ são mencionados por Beltrán (1986) para solos classificados texturalmente como areia muito fina. Valores de $\mathrm{K}_{0}=0,12 \mathrm{~m} \mathrm{~d}^{-1}$ a K $=49 \mathrm{~m} \mathrm{~d}^{-1}$ podem ser encontrados em áreas aluviais tão pequenas quanto 5 ha (Davenport et al., citados por Bentley et al. 1989).

Os valores de $\mathrm{K}_{0}$ num perfil superior de solo variam com o tempo, por causa da secagem do perfil superior durante a estação seca ou após a ação da drenagem (natural ou artificial). Os valores de $\mathrm{K}_{0}$ do perfil inferior (ou subsolo) são menos variáveis com o tempo porque eles estão menos sujeitos ao processo de secagem e umedecimento do solo, e o processo de ação biológica é menos intenso. A variabilidade sazonal ocorre principalmente em solos com alto teor de argila e fração orgânica, devido a mudanças periódicas na estrutura e porosidade do solo, que dependem, fundamentalmente, das condições prevalecentes dos subsistemas água-solo.

$\mathrm{Na}$ classificação dos materiais de solo constituintes dos horizontes correspondentes às profundidades dos testes nos 19 pontos (Tabela 1) verificam-se variações em todas as frações, o que confirma a desuniformidade nos valores de $\mathrm{K}_{0}$ na direção horizontal (Figura 3).

A princípio, a ampla variação constatada na condutividade hidráulica atribui-se, em parte, à gênese e evolução do solo estudado, que aconteceram através de processos de sedimentação aluvial durante o seu desenvolvimento hidrogeológico.

Os resultados desta pesquisa sugerem um estudo mais detalhado em campo, utilizando-se um método mais abrangente como o da descarga dos drenos, agregando-se a condutividade hidráulica a outros parâmetros físicos de solo, estudados para fins de drenagem; por exemplo, como se explica que em solos de várzeas com perfil de classificação textural argiloso, Coelho et al. (1986) tenham encontrado um valor de $\mathrm{K}_{0}$ igual a $0,03 \mathrm{~m} \mathrm{~d}^{-1}$, para uma região, e para outra, com o mesmo tipo de solo e a mesma classificação textural, $\mathrm{K}_{0}$ igual a $0,28 \mathrm{~m} \mathrm{~d}^{-1}$ ? Beltrán (1986), com 


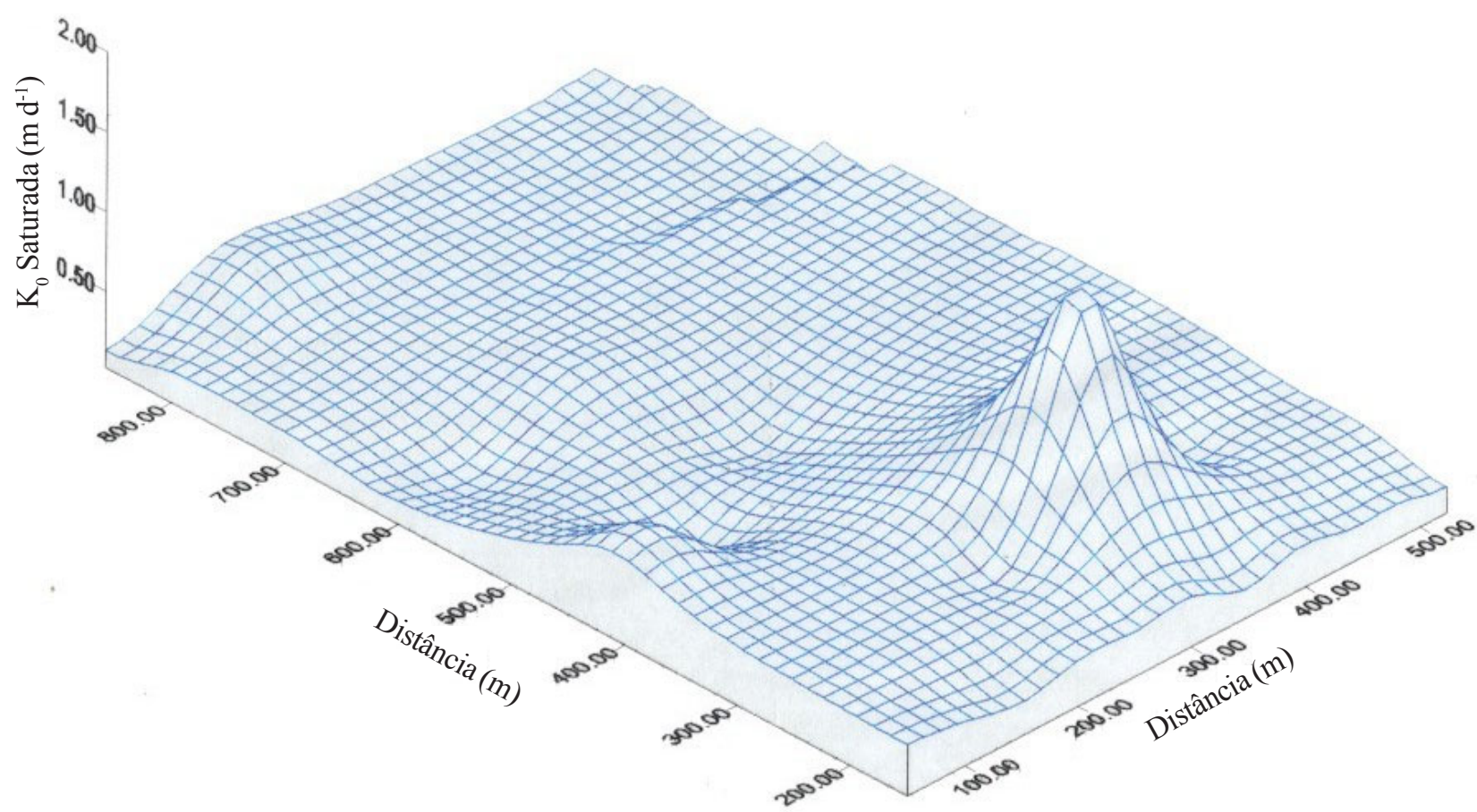

Figura 3. Superfície de valores da variabilidade espacial na extensão da área retangular, contendo 18 ha da área dos testes de condutividade hidráulica saturada, $\mathrm{K}_{0,}$ num solo aluvial do Perímetro Irrigado de São Gonçalo, PB

base em informações do United States Bureaux of Reclamation, tem relacionado a condutividade hidráulica e a porosidade drenável com a textura e a estrutura do solo. Libardi (1995) abordando sobre condutividade hidráulica do solo saturado esclarece a necessidade implícita de se entender esta mesma dinâmica, embora para uma unidade amostral de solo por fluir uma solução aquosa.

\section{CONCLUSÃO}

Constataram-se grandes variações espaciais, horizontal e vertical, nos valores da condutividade hidráulica saturada, no solo aluvial estudado atribuídas, em parte, à gênese e à evolução do solo local, devido aos processos de sedimentação aluvial.

\section{LITERATURA CITADA}

Back, A.J.; Ferreira, P.A.; Sediyama, G.C.; Vieira, M. Sistemas de drenagem em regime variável. Revista Ceres, Viçosa, v.37, n.209, p.36-49, 1990.
Beltrán, J.M. Drenaje agricola. Madrid: Ministerio da Agricultura, Pesca y Alimentacion, 1986. v.1.239p.

Bentley, W.J.; Skaggs, R.W.; Parsons, J.E. The effect of variation in hydraulic conductivity on watertable drawdown. Technical Bulletin, North Carolina Agricultural Research Service. North Carolina State University, 288, Raleigh, 23p. 1989.

Coelho, E.F.; Euclydes, H.P.; Campos Neto, S. Engenharia de drenagem na agricultura. Informe Agropecuário, Belo Horizonte, v.12, n.139, p.68-80, 1986.

El-Mowellhi, N.M.; van Shilfgaarde, J. Computation of soil hydrological constants from field drainage experiments in some soils in Egypt. Transactions of the ASAE, St. Joseph, v.25, p.77-79. 1982.

Libardi, P.L. Dinâmica de água no solo. Piracicaba, 1995. 497p.

Millar, A.A. Drenagem de terras agrícolas: Bases agronômicas. São Paulo: Editora, 1988. 306p.

Pizarro, F. Drenaje agrícola y recuperacion de suelos salinos. Madrid: Agricola Española, 1978. 521 p. 